\title{
Associations between early childhood caries, malnutrition and anemia: a global perspective
}

\author{
Morenike Oluwatoyin Folayan ${ }^{1 *}$, Maha El Tantawi ${ }^{2}$, Robert J. Schroth ${ }^{3,4+}$ (D) Ana Vukovic ${ }^{5+}$, Arthur Kemoli ${ }^{6}$, \\ Balgis Gaffar ${ }^{7}$, Mary Obiyan ${ }^{8}$ and Early Childhood Caries Advocacy Group
}

\begin{abstract}
Background: Malnutrition is the main risk factor for most common communicable diseases. The aim of this study is to determine the relationship between country-level prevalence of early childhood caries (ECC), malnutrition and anemia in infants and preschool children.

Methods: Matched country-level ECC, malnutrition and anemia prevalence were generated from databases covering the period 2000 to 2017. Multivariate general linear models were developed to assess the relationship between outcome variables (prevalence of stunting, wasting, overweight, and anemia) and the explanatory variable (ECC prevalence) adjusted for gross national income per capita. Adjusted regression coefficients (B) and partial eta squared were computed.

Results: The mean (standard deviation (SD)) ECC prevalence was 23.8 (14.8)\% for 0-2 year-olds and 57.3 (22.4)\% for 3-5year-olds. The mean (SD) prevalence of wasting was $6.3(4.8) \%$, overweight $7.2(4.9) \%$, stunting $24.3(13.5) \%$, and anemia $37.8(18.1) \%$. For $0-2$-year-olds, the strongest and only significant association was between the prevalence of ECC and overweight $(\eta 2=0.21): 1 \%$ higher ECC prevalence was associated with $0.12 \%$ higher prevalence of overweight $(B=0.12$, $P=0.03)$. In 3-5-year-olds, the strongest and only significant association was between the prevalence of ECC and anemia ( $n 2=0.08): 1 \%$ higher prevalence of ECC was associated with $0.14 \%$ lower prevalence of anemia $(B=-0.14, P=0.048)$.

Conclusion: Country-level prevalence of ECC was associated with malnutrition in 0-2-year-olds and with anemia in 3-5year-olds. The pathway for the direct relationship between ECC and overweight may be diet related. The pathway for the inverse relationship between ECC and anemia is less clear and needs further investigations.
\end{abstract}

Keywords: Stunting, Overweight, Underweight, Free sugar, Gross National Income per capita

\section{Background}

There are global concerns about the multi-facet impact of malnutrition in children. The term malnutrition includes undernutrition (underweight, wasting, stunting, micronutrient deficiencies and low birth weight), which is present most often in disadvantaged communities, and

\footnotetext{
* Correspondence: toyinukpong@yahoo.co.uk

${ }^{\dagger}$ Robert J. Schroth and Ana Vukovic contributed equally to this work. ${ }^{1}$ Department of Child Dental Health, Obafemi Awolowo University, Ile-Ife, Nigeria

Full list of author information is available at the end of the article
}

over consumption of food (overweight and obesity), which is present in both developed and developing communities [1]. Malnutrition is the main risk factor for most common communicable diseases and contributes to acute deaths in children under five years of age [2]. On the other hand, overweight and obesity increase the risk for non-communicable diseases, poor adulthood health, and premature death [1].

Early childhood caries (ECC) is dental decay that affects the primary dentition in children younger than 6 years of age [3]. It is a challenging problem faced by

(c) The Author(s). 2020 Open Access This article is licensed under a Creative Commons Attribution 4.0 International License, which permits use, sharing, adaptation, distribution and reproduction in any medium or format, as long as you give appropriate credit to the original author(s) and the source, provide a link to the Creative Commons licence, and indicate if changes were made. The images or other third party material in this article are included in the article's Creative Commons licence, unless indicated otherwise in a credit line to the material. If material is not included in the article's Creative Commons licence and your intended use is not permitted by statutory regulation or exceeds the permitted use, you will need to obtain permission directly from the copyright holder. To view a copy of this licence, visit http://creativecommons.org/licenses/by/4.0/. The Creative Commons Public Domain Dedication waiver (http://creativecommons.org/publicdomain/zero/1.0/) applies to the data made available in this article, unless otherwise stated in a credit line to the data. 
infants, toddlers and preschool children in developed and developing countries [4]. Severe forms of ECC impact children's growth, development, and well-being [5], and can have negative social and economic effects on parents and society [6]. Malnutrition has many of the same etiological factors as ECC, including poor dietary habits and food intake, and social-economic inequalities [7]. If not addressed, ECC can destroy the primary dentition causing oral pain that can interfere with eating and sleeping. These consequences can result in a child being underweight [8,9] and stunted [10]. Also, vitamin D, iron, calcium and albumin deficiencies and proteinenergy malnutrition may lead to enamel defects that make the enamel surface rough and prone to accumulation of plaque, with subsequent post-eruptive caries [11, 12]. Malnutrition can also cause salivary gland hypofunction, with reduced saliva flow rate and buffering capacity $[13,14]$, and change in salivary constituents ratio, particularly amylase, lysozyme, and immunoglobulins. These changes are associated with higher risk of caries [15-19]. Thus, the relationship between malnutrition and ECC is complex, bi-directional and involves comorbid relationships [7].

Recent studies have highlighted the relationship between ECC and malnutrition [20], micronutrient deficiencies [11, 12, 21-23], and anemia (which may result from malnutrition [24]). However, most of the evidence on the relationship between ECC, malnutrition and anemia is inconclusive. To the best of our knowledge, the scientific literature lacks macro-level data on the relationship between these three public health issues that have shared etiological factors. Understanding these relationships might help in to designing cost-effective and efficient interventions using the common risk factor approach, and targeting at-risk children in parts of the world where the problems are most concentrated [20].

The purpose of this study was to determine the association between country-level prevalence of ECC with malnutrition and anemia in infants and preschool children. The null hypothesis of the study was that ECC prevalence in 0 to 2 -year-olds and 3 to 5 -year-olds is not associated with malnutrition or anemia.

\section{Methods}

This was an ecologic study. We collected macro-level data about ECC, anemia and nutritional status of children under six years of age for the period January 2007 to October 2017 for United Nations member States [25].

\section{Data sources}

\section{Prevalence of ECC}

According to the American Academy of Pediatric Dentistry, children $<72$ months of age with one or more decayed, missing due to decay or filled primary tooth surfaces have ECC [3]. The data on ECC prevalence were extracted from the World Health Organization (WHO) Country Oral Health Profile database and other online databases. Most estimates of ECC were based on cavitated lesions only and they were included in the study data. No language filter was applied for the database search. The retrieved data were used to calculate the ECC prevalence for each country by dividing the total number of children affected with ECC by the total number of children examined multiplied by 100 . Most retrieved studies did not provide estimates of ECC severity such as the number of affected teeth/surfaces or the number of teeth/surfaces that were filled or missing. Thus, the data used were only the prevalence of ECC prevalence. Prevalence was calculated for two separate age groups: $0-2$ and 3-5-year-olds. More details on the computation of country level ECC prevalence were reported in our previous paper [26].

\section{Nutritional status of children under- 5 years}

Information on nutritional status was obtained from country-level data jointly produced by the WHO, UNICEF and World Bank in 2018 [27, 28] covering the period 2000 to 2017. The thresholds for defining stunting, wasting and overweight were established through the WHO-UNICEF Technical Advisory Group on Nutrition Monitoring [27] and were developed in relation to standard deviations (SD) of the normative WHO Child Growth Standards. We used the following definitions applying to children aged $0-5$ years old:

1. Stunting: below minus two SDs from median height-for-age.

2. Wasting: below minus two SDs from median weight-for-height.

3. Overweight: above one SD from median weight-forheight.

The prevalence of wasting, stunting and overweight were reported as the percentage of children $0-5$ years old who met the definition.

\section{Anemia status in children under-5 years of age}

We used country-level estimates for anemia prevalence from the WHO [29], where iron-deficiency anemia was defined as blood hemoglobin concentrations $<110 \mathrm{~g} / \mathrm{l}$ in children younger than 5 years of age.

\section{Data analysis}

The data sets (ECC, malnutrition, and anemia indicators) were matched by country. Scatter plots were used to represent the correlation between the prevalence of anemia, malnutrition and ECC in the two age groups (0-2-year-olds and 3-5-year-olds), and correlation 
coefficients and $p$ values were calculated. Multivariate analysis of variance (MANOVA) with the SPSS procedure multivariate general linear analysis was used to develop two separate models assessing the relationship between outcome variables (prevalence of types of malnutrition; and prevalence of anemia) and two explanatory variables (ECC prevalence) for each two-age group. Each model was adjusted for the economic level of the country according to the 2017 Gross National Income per capita calculated with the World Bank Atlas method [30] based on our previous finding of the association between global ECC prevalence and growth in per capita gross national income [26]. The groups were: low income (\$995 or less); lower middle income (\$996-3895); upper middle income (\$3896-12,055); and high income (\$12,056 or more). Adjusted regression coefficients (B), confidence intervals (CIs), $p$ values and partial eta squared $\left(\eta^{2}\right.$ as measure of effect size) were computed. Residual plots were assessed for the randomness of residuals' distribution to ensure that model assumptions apply. Variance inflation factors were calculated to assess collinearity. Significance level was set at 5\%. Statistical analyses were performed with SPSS version 22.0 (IBM Corp., Armonk, N.Y., USA).

\section{Results}

ECC data were available for 39 countries for 0-2-yearolds and for 86 countries for 3-5-year-olds. Data on malnutrition and anemia were available for 128-185 countries, depending on malnutrition type. Combined ECC, anemia and malnutrition data were available for 26 countries in the age $0-2$-years-old and 55 countries in the age 3-5-years-old (See Supplement 1 for list of countries). Thus, the results in this study are based on analysis of data from 26 and 55 countries in the 0-2year-old group and the 3-5-year-old group, respectively.

The mean (SD) ECC prevalence was $23.8(14.8) \%$ in 0 -2-year-old children and 57.3 (22.4)\% in 3-5-year-old children. The overall mean (SD) prevalence of wasting was $6.3(4.8) \%$, of overweight was $7.2(4.9) \%$, of stunting was $24.3(13.5) \%$, and of anemia was $37.8(18.1) \%$.

The 26 countries that had complete data on ECC, anemia and malnutrition for 0-2-year-olds were two (7.7\%) low-income countries, 10 (38.5\%) lower middleincome countries, nine (34.6\%) upper middle-income countries, and five (19.2\%) high-income countries. The 55 countries that had complete data on ECC, anemia and malnutrition for 3-5-year-olds were six (10.9\%) low-income countries, 19 (34.5\%) lower middle-income countries, 22 (40\%) upper middle-income countries, and eight (14.5\%) high-income countries.

Figure 1(a) illustrates that ECC prevalence for 0-2year-olds was positively, weakly and non-significantly correlated with the prevalence of wasting $(\mathrm{r}=0.17, P=$
$0.40)$, stunting $(\mathrm{r}=0.09, P=0.68)$, and anemia $(\mathrm{r}=0.14$, $P=0.39$ ). The prevalence of overweight was positively, moderately and significantly correlated with the prevalence of ECC ( $r=0.47, P=0.02)$.

Figure 1(b) reveals that among 3-5-year-olds, ECC prevalence was positively, weakly and non-significantly correlated with the prevalence of wasting $(\mathrm{r}=0.12, \mathrm{P}=$ $0.40)$, stunting $(\mathrm{r}=0.15, P=0.29)$, and overweight $(\mathrm{r}=$ $0.09, P=0.51$ ). However, the prevalence of anemia was positively, weakly and significantly correlated with the prevalence of ECC $(r=0.25, P=0.02)$.

Results of the multivariate general linear analysis controlled for economic level are reported in Table 1. For children 0-2-years of age, the greatest effect size and only significant association was between the prevalence of ECC and the prevalence of overweight $(\eta 2=0.21)$; where countries with $1 \%$ higher ECC prevalence had a $0.12 \%$ higher prevalence of overweight $(\mathrm{B}=0.12, P=$ 0.03 ). For children $3-5$ years of age, the greatest effect size and only significant association was between the prevalence of ECC and the prevalence of anemia $(\eta 2=$ $0.08)$, where countries with $1 \%$ higher prevalence of ECC had a $0.14 \%$ lower prevalence of anemia $(B=-$ $0.14, P=0.048$ ). No collinearity was observed (variance inflation factors $<5$ ).

\section{Discussion}

To our knowledge, this study provides the first evidence on the relationship between country-level prevalence of ECC, malnutrition, and anemia. However, not all types of malnutrition were associated with ECC. We found a positive and significant relationship between countrylevel prevalence of overweight and ECC in children 0-2years of age, with higher prevalence of overweight associated with higher ECC prevalence. There was also an inverse relationship between country-level prevalence of anemia and ECC in 3-5-years olds with lower prevalence of anemia in countries with higher prevalence of ECC.

Overweight was associated with ECC only in children $\leq 2$-years of age. The relationship between ECC, and childhood growth and development is not clear $[5,31]$. The studies on the relationship between ECC and nutritional status provide conflicting results - some found no association [32-34], others found a positive association and some had inconclusive results [31, 35]. Recent Canadian studies reported that preschool children with severe ECC who were undergoing dental rehabilitation were more likely to have higher BMI z-scores than were caries-free controls [11, 12, 21, 23]. The inconsistent findings of the previous studies may be due to differences in the methods used for nutritional assessments, age range cut-offs, and confounders of dental caries, 

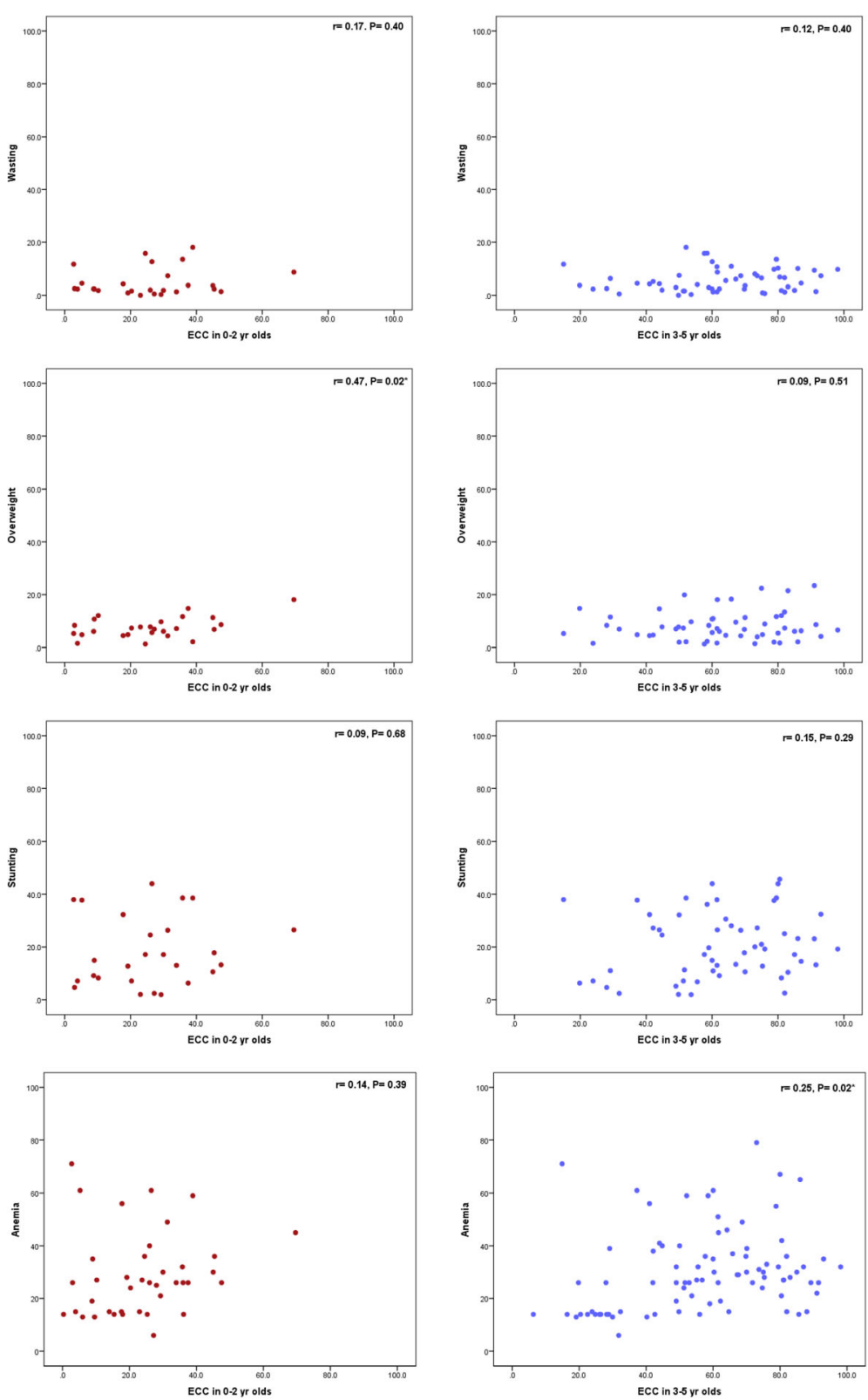

(a)

(b)

Fig. 1 Scatter plots for the correlation between prevalence of malnutrition indicators, anemia and ECC in (a) 0-2 year-old children and (b) 3-5 year-old children

Table 1 Association between prevalence of ECC in 0 to 2-year-olds and 3 to 5-year-olds, anemia and malnutrition

\begin{tabular}{|c|c|c|c|c|c|c|}
\hline \multirow[t]{2}{*}{ Malnutrition } & \multicolumn{3}{|c|}{ ECC prevalence in $0-2$ year olds } & \multicolumn{3}{|c|}{ ECC prevalence in $3-5$ year olds } \\
\hline & B $(95 \% \mathrm{Cl})$ & $P$ & $\eta 2$ & B $(95 \% \mathrm{Cl})$ & $P$ & $\eta 2$ \\
\hline Wasting & $-0.02(-0.14,0.11)$ & 0.76 & 0.004 & $0.001(-0.06,0.06)$ & 0.98 & $<0.0001$ \\
\hline Overweight & $0.12(0.02,0.23)$ & $0.03^{*}$ & 0.21 & $0.02(-0.06,0.09)$ & 0.65 & 0.004 \\
\hline Stunting & $-0.05(-0.31,0.21)$ & 0.68 & 0.008 & $-0.01(-0.14,0.11)$ & 0.84 & 0.001 \\
\hline Anemia & $-0.15(-0.48,0.19)$ & 0.38 & 0.04 & $-0.14(-0.29,-0.001)$ & $0.048^{*}$ & 0.08 \\
\hline
\end{tabular}

Multivariate general linear models were adjusted for income levels. For 0-2-year- olds: $p$ value for income association with dependent variables $<0.05$ except with overweight where $P=0.76$. For $3-5$-year-olds, $\mathrm{p}$ value for income association with dependent variables $<0.05$ for all

१2: partial eta squared

*: statistically significant at $P<0.05$ 
including differences in definition and severity of ECC [33].

The higher prevalence of overweight in countries with higher estimates of ECC in 0-2-year-olds may reflect the findings by El Tantawi et al. [26] who reported a higher prevalence of ECC in countries with greater economic growth. ECC and overweight/obesity share common risk factors - high frequency and quantity of free sugar consumption [36], food insecurity [37, 38], low socioeconomic status [39-41], residence in urban slums $[42,43]$ and rural areas $[44,45]$. Growing economies are most likely to be undergoing nutrition transitions from traditional diets to low quality, processed, high-sugar, high-fat, carbohydrate-dense food and beverages that are poor in micronutrients $[46,47]$, which predisposes to overweight and high ECC prevalence. Our results might suggest that having ECC and being overweight have shared risk factors that are related to the macroeconomic status of the country. A common risk factor approach [20,48] may be used to address both ECC and overweight problems; with global action to control these health problems given priority to countries with greater economic growth.

The few studies that have assessed the relationship between ECC and nutritional status often included age ranges larger than that of ECC. Four studies conducted amongst preschool children, found no association between ECC and overweight in children 3 years of age [49], 2-5-year-olds [50], and 2-6-year-olds [51, 52]. These findings highlight the need for appropriate age groupings when studying ECC, as the relationship between ECC and nutritional status seems to be modulated by age. However, Davidson et al. [21] found that severe ECC was associated with obesity in 2-5-year-olds, thereby highlighting two additional dimensions to determining the association between ECC and overweight the severity of ECC and the severity of overweight. Interestingly, those authors found an association between the two extremes of the phenomena studied. This finding also implies that enrolling children who have milder forms of caries and nutritional status may underestimate potential relationships [21]. Therefore, we suggest that future studies on ECC and nutritional status not only ensure that ECC is analyzed by age groups $0-2$-year-olds and 3-5-year-olds, but also ensure that ECC and malnutrition data include the extremes of the variables, with emphasis on severe levels of ECC, such as those data using the World Health Organization Significant Caries Index. We exercise caution that the correlation we observed may be an artifact as correlational analysis at the macro-level is usually larger than it is for individuals [53].

Anemia, which is a complication of malnutrition and factors not malnutrition related [24, 36], was inversely associated with ECC in older preschool children. Anemia may not be a direct result of ECC, but it may be related to increased milk consumption in early childhood [23]. Evidence suggests that in developed countries where milk intake is high, the risk of anemia also is high [54, 55]. Anemia from high milk intakes results from early weaning of the child, and introduction of foods with low iron bioavailability. Milk also impairs nonheme and heme iron absorption [56]. Recent Canadian studies, a developed country that do not have malnutrition as a major health crisis [57] and have lower prevalence of ECC [58], reported that preschool children with severe ECC undergoing dental rehabilitation were more likely to have iron deficiency anemia than were cariesfree controls [11, 12, 21, 23]. Future studies should explore this finding.

The present findings may have implications at the microlevel. Malnutrition is a complex disorder not solely caused by lack of food [59]. Feeding practices and other risk factors leading to malnutrition and/or anemia may be associated with greater risk for ECC. Health education programs to improve parental dietary choices and provision of sponsored healthful meals in kindergartens and similar gatherings may contribute to reducing the risk of these diseases but may not eliminate it. In addition, health providers who manage malnutrition, anemia and ECC could provide better and more comprehensive care to children by screening for either of the diseases and referring children to for specialized care. Structuring primary health care services to provide integrated dental and pediatric care may help address the dual burden of ECC and malnutrition. Dentists who care for patients with severe ECC should be aware that the children may have undiagnosed nutritional disease that warrants investigation.

One of the strengths of this study is that collated data on malnutrition included high-quality data from the Demographic Health Survey [60]. However, there is the risk of over-representation of children who have living mothers since the anthropometric variables used for assessment of nutritional status are only available for those who are alive: the sample may therefore have underrepresented malnutrition in infants and preschool children [61, 62]. We controlled for gross national income per capita, but we could not control for all possible confounders, as these remain largely unknown due to lack of data. One of the confounders is sex, which plays a role in nutrition [63], but its role as a risk factor for ECC is unknown. We also were not able to adjust for possible confounders like sugar intake and oral hygiene status as country-level data for these variables were not available. Controlling for these factors may attenuate the relationships we established in this study. Our use of the z-scores adjusted for age and sex to determine nutritional status allowed for more meaningful reporting of means [21]. We 
did not use the body mass index to assess nutritional status because it is meant to be used in children $\geq 2$ years of age whereas we focused on 2-year-olds and younger, in addition to children $>2$ years of age.

A limitation of this study was use of the World Health Organization's criteria for assessing caries by many of the epidemiological surveys [64]. This assessment tool does not include non-cavitated lesions: only $15 \%$ of ECC surveys reported non-cavitated and/or cavitated as the caries detection level [36]. The ECC prevalence for many countries may therefore be under-reported. Our study analysis was also limited by only a minor portion of the global ECC prevalence estimates being based on national surveys, which made generalizability of the study findings challenging. ECC is under-studied in many parts of the world and true population estimates are often unknown. Also, although we split the data on ECC into two age groups - 0-2 and 3-5-year-olds - estimates for wasting, stunting and overweight could not be split because the data were not available. Further, our study is cross-sectional, so the direction of the observed relationships cannot be ascertained i.e., whether ECC increases the risk of 0-2-year-old children being overweight, or being overweight increases the risk for ECC. A carefully designed longitudinal study may answer the questions this study have raised but were unanswered.

\section{Conclusion}

Country-level prevalence of ECC was associated with malnutrition in 0-2-year-olds and with anemia in 3-5year-olds. We also observed age-related disparities in the relationship between ECC, malnutrition, and anemia. The disparities reiterate the need for future analysis of ECC-related data for the two age groups as earlier highlighted by El Tantawi et al. [26]. Further, prospective studies are needed to determine how various social, economic and cultural factors that characterize these age groups impact the co-morbid existence of the three diseases. Though prior research findings suggests that the pathway for the direct relationship between ECC and overweight may be diet related, the pathway for the inverse relationship between ECC and anemia is less clear and needs further investigations The small magnitude of the associations suggest that other factors may modulate the association between ECC, anemia and overweight. Longitudinal studies assessing the relationship between separate age groups, ECC severity and severity of malnutrition is necessary to understand the relationship between ECC, malnutrition, and anemia. Understanding these relationships might aid in the designing of costeffective and efficient global preventive interventions using the common risk factor approach for infants and preschool children.

\section{Supplementary information}

Supplementary information accompanies this paper at https://doi.org/10. 1186/s40795-020-00340-Z.

Additional file 1. Countries with complete data on early childhood caries, anemia and malnutrition.

\section{Abbreviations}

Cl: Confidence Interval; ECC: Early Childhood Caries; UNICEF: United Nations Children's Emergency Funds; SD: Standard Deviation; WHO: World Health Organization

\section{Acknowledgements}

Dr. Schroth holds a Canadian Institute of Health Research Embedded Clinician Researcher position in "improving access to care and oral health service delivery for young children in Manitoba".

\section{Authors' contributions}

MOF conceptualized and designed the study, coordinated the data analysis, drafted the initial manuscript, and critically reviewed and revised the manuscript for important intellectual content. ME conceptualized and designed the study, designed the data collection instruments, collected data, carried out the analyses, and reviewed and revised the manuscript. RS and AV conceptualized and designed the study, made inputs into the data analyses plan, and reviewed and revised drafts of the manuscript. AK, BG and MO made inputs into the data analyses plan, and reviewed and revised drafts of the manuscript. All authors read and approved the final manuscript.

Funding

No funding was obtained for this study.

\section{Availability of data and materials}

Study related data and materials are enclosed as supplementary file. The complete details on the ECC prevalence by age group and country is available as a supplementary file of the publication by: El Tantawi M, Folayan MO, Mehaina M, Vukovic A, Castillo JL, Gaffar BO, et al. Prevalence and Data Availability of Early Childhood Caries in 193 United Nations Countries, 20072017. American journal of public health. 2018; 108(8):1066-1072. The nutrition related data is accessible at: https://data.unicef.org/topic/nutrition/ malnutrition/. Published 2018. Updated May 2018. The anemia related data is accessible at: WHO. The global prevalence of anemia in 2011. https://www. who.int/nutrition/publications/micronutrients/global_prevalence_anaemia_2 011/en/. Published 2015.

Ethics approval and consent to participate

Not applicable. Public accessible data was used for the study.

Consent for publication

Not applicable.

\section{Competing interests}

The authors declare that Morenike Oluwatoyin Folayan and Maha El Tantawi are Sectional and Associate editors with BMC Oral Health, respectively.

\section{Author details}

'Department of Child Dental Health, Obafemi Awolowo University, lle-lfe, Nigeria. ${ }^{2}$ Department of Pediatric Dentistry and Dental Public Health, Faculty of Dentistry, Alexandria University, Alexandria, Egypt. ${ }^{3}$ Department of Preventive Dental Science, Dr. Gerald Niznick College of Dentistry, University of Manitoba, Winnipeg, Canada. ${ }^{4}$ Departments of Pediatrics and Child Health and Community Health Sciences, Max Rady College of Medicine, Rady Faculty of Health Sciences, University of Manitoba, Winnipeg, Canada. ${ }^{5}$ Department of Pediatric and Preventive Dentistry, School of Dental Medicine, University of Belgrade, Belgrade, Serbia. ${ }^{6}$ Department of Paediatric Dentistry and Orthodontics, University of Nairobi, Nairobi, Kenya. ${ }^{7}$ Department of Preventive Dental Sciences, College of Dentistry, Imam Abdulrahman University, Dammam, Saudi Arabia. ${ }^{8}$ Department of Demography and Social Statistics, Obafemi Awolowo University, Ile-lfe, Nigeria. 
Received: 21 October 2019 Accepted: 5 March 2020

\section{Published online: 04 May 2020}

\section{References}

1. WHO. Action plan to reduce the double burden of malnutrition in the Western Pacific Region. (2015-2020). http://iris.wpro.who.int/handle/1 0665.1/10892. Published 2015.

2. Rice AL, Sacco L, Hyder A, Black RE. Malnutrition as an underlying cause of childhood deaths associated with infectious diseases in developing countries. Bull World Health Organ. 2000;78(10):1207-21.

3. AAPD. Policy on Early Childhood Caries (ECC): Classifications, Consequences, and Preventive Strategies. Pediatr Dent. 2017;39(6):59-61.

4. Manton DJ. Child dental caries - a global problem of inequality. EClinicalMedicine. 2018;1:3-4

5. Schroth RJ, Harrison RL, Moffatt ME. Oral health of indigenous children and the influence of early childhood caries on childhood health and well-being. Pediatr Clin N Am. 2009;56(6):1481-99.

6. Jabbarifar SE, Ahmady N, Sahafian SA, Samei F, Soheillipour S. Association of parental stress and early childhood caries. Dental Res J. 2009;6(2):65-70.

7. Dimaisip-Nabuab J, Duijster D, Benzian H, Heinrich-Weltzien R, Homsavath A, Monse B, et al. Nutritional status, dental caries and tooth eruption in children: a longitudinal study in Cambodia, Indonesia and Lao PDR. BMC Pediatrics. 2018;18(1):300.

8. Psoter WJ, Reid BC, Katz RV. Malnutrition and dental caries: a review of the literature. Caries Res. 2005;39(6):441-7.

9. So M, Ellenikiotis YA, Husby HM, Paz CL, Seymour B, Sokal-Gutierrez K. Early Childhood Dental Caries, Mouth Pain, and Malnutrition in the Ecuadorian Amazon Region. Int J Environ Res Public Health. 2017:14(5).

10. Penafiel D, Termote C, Lachat C, Espinel R, Kolsteren P, Van Damme P. Barriers to eating traditional foods vary by age Group in Ecuador with Biodiversity Loss as a key issue. J Nutr Educ Behav. 2016;48(4):258-68 e251.

11. Schroth $\mathrm{R}$, Jeal $\mathrm{N}$, Kliewer $\mathrm{E}$, Sellers $\mathrm{E}$. The relationship between vitamin D and severe early childhood caries: a pilot study. Int J Vitam Nutr Res. 2012; 82(1):53-62.

12. Schroth RJ, Levi JA, Sellers EA, Friel J, Kliewer E, Moffatt ME. Vitamin D status of children with severe early childhood caries: a case-control study. BMC Pediatr. 2013:13:174.

13. Johansson I, Lenander-Lumikari M, Saellstrom AK. Saliva composition in Indian children with chronic protein-energy malnutrition. J Dent Res. 1994; 73(1):11-9.

14. Johansson I, Saellstrom AK, Rajan BP, Parameswaran A. Salivary flow and dental caries in Indian children suffering from chronic malnutrition. Caries Res. 1992;26(1):38-43.

15. Agarwal PK, Agarwal KN, Agarwal DK. Biochemical changes in saliva of malnourished children. Am J Clin Nutr. 1984;39(2):181-4.

16. Alvarez JO, Lewis CA, Saman C, Caceda J, Montalvo J, Figueroa ML, et al. Chronic malnutrition, dental caries, and tooth exfoliation in Peruvian children aged 3-9 years. Am J Clin Nutr. 1988;48(2):368-72.

17. Cleaton-Jones $P$, Richardson BD, Granath L, Fatti LP, Sinwell R, Walker AR, et al. Nutritional status and dental caries in a large sample of 4- and 5-yearold South African children. S Afr Med J. 2000;90(6):631-5.

18. Li Y, Navia JM, Bian JY. Caries experience in deciduous dentition of rural Chinese children 3-5 years old in relation to the presence or absence of enamel hypoplasia. Caries Res. 1996;30(1):8-15.

19. Lingstrom P, Moynihan P. Nutrition, saliva, and oral health. Nutrition. 2003; 19(6):567-9.

20. Sokal-Gutierrez K, Turton B, Husby H, Leonor PC. Early childhood caries and malnutrition: baseline and two-year follow-up results of a community-based prevention intervention in rural Ecuador. BMC Nutr. 2016;2:73.

21. Davidson K, Schroth RJ, Levi JA, Yaffe AB, Mittermuller BA, Sellers EAC. Higher body mass index associated with severe early childhood caries. BMC Pediatr. 2016;16:137

22. Schroth RJ, Lavelle C, Tate R, Bruce S, Billings RJ, Moffatt ME. Prenatal vitamin D and dental caries in infants. Pediatrics. 2014;133(5):e1277-84.

23. Schroth RJ, Levi J, Kliewer E, Friel J, Moffatt ME. Association between iron status, iron deficiency anaemia, and severe early childhood caries: a case-control study. BMC Pediatr. 2013;13(1):22.

24. Bansal K, Goyal M, Dhingra R. Association of severe early childhood caries with iron deficiency anemia. J Indian Soc Pedod Prev Dent. 2016; 34(1):36-42.
25. UN. Member States. United Nations; [assessed 2018 August 26] http://www. un.org/en/member-states/. Published 2017.

26. El Tantawi M, Folayan MO, Mehaina M, Vukovic A, Castillo JL, Gaffar BO, et al. Prevalence and data availability of early childhood caries in 193 United Nations countries, 2007-2017. Am J Public Health. 2018;108(8):1066-72.

27. United Nations Children's Fund, World Health Organization, World Bank Group. Levels and trends in child malnutrition: Key findings of the 2018 Edition of the Joint Child Malnutrition Estimates. https://data.unicef.org/wpcontent/uploads/2018/05/JME-2018-brochure-web.pdf. Published 2018.

28. UNICEF. Malnutrition in Children - UNICEF DATA. https://data.unicef.org/ topic/nutrition/malnutrition/. Published 2018. Updated May 2018. Accessed 16th February, 2019.

29. WHO. The global prevalence of anemia in 2011. https://www.who.int/ nutrition/publications/micronutrients/global_prevalence_anaemia_2011/en/. Published 2015. Accessed 16th February, 2019.

30. TheWorldBankGroup. List of economies in 2018. databank.worldbank.org/ data/download/site-content/CLASS.xls. Published 2018. Accessed February, 2019

31. Xavier A, Bastos da Silva R, Arakawa AM, Caldana de Lourdes A, Bastos de Magalhaes JB. Correlation between dental caries and nutritional status: preschool children in a Brazilian municipality. The Revista de Odontologia da UNESP. 2013;42(5):378-83.

32. Li LW, Wong HM, Peng SM, McGrath C. Anthropometric measurements and dental caries in children: a systematic review of longitudinal studies. Adv Nutr. 2015;6(1):52-63.

33. Seow WK, Clifford H, Battistutta D, Morawska A, Holcombe T. Case-control study of early childhood caries in Australia. Caries Res. 2009:43(1):25-35.

34. Werner SL, Phillips C, Koroluk LD. Association between childhood obesity and dental caries. Pediatr Dent. 2012;34:23-7.

35. Sullivan JM, Bicego GT, Rutstein SO. Assessment of the quality of data used for the direct estimation of infant and child mortality in the Demographic and Health Surveys. In: An assessment of DHS-I data quality DHS Methodological Reports No 1. Columbia: Institute for Resource Development / Macro Systems, Inc.; 1991. p. 113-43.

36. Dye BA, Hsu KL, Afful J. Prevalence and measurement of dental caries in young children. Pediatr Dent. 2015;37:200-16

37. Angelopoulou MV, Shanti SD, Gonzalez CD, Love A, Chaffin J. Association of food insecurity with early childhood caries. J Public Health Dent. 2019;79(2): 102-8.

38. von Braun J. Food insecurity, hunger and malnutrition: necessary policy and technology changes. New Biotechnol. 2010;27(5):449-52.

39. Chankanka O, Cavanaugh JE, Levy SM, Marshall TA, Warren JJ, Broffitt B, et al. Longitudinal associations between children's dental caries and risk factors. J Public Health Dent. 2011;71(4):289-300.

40. Peltzer K, Mongkolchati A, Satchaiyan G, Rajchagool S, Pimpak T. Sociobehavioral factors associated with caries increment: a longitudinal study from 24 to 36 months old children in Thailand. Int J Environ Res Public Health. 2014;11(10):10838-50.

41. Van de Poel E, Hosseinpoor AR, Speybroeck N, Van Ourti T, Vega J. Socioeconomic inequality in malnutrition in developing countries. Bull World Health Organ. 2008;86(4):282-91.

42. Chakraborty M, Saha JB, Bhattacharya RN, Roy A, Ram R. Epidemiological correlates of dental caries in an urban slum of West Bengal. Indian J Public Health. 1997:41(2):56-60 67.

43. Sawaya AL, Dallal G, Solymos $G$, de Sousa MH, Ventura ML, Roberts SB, et al. Obesity and malnutrition in a Shantytown population in the city of Sao Paulo, Brazil. Obesity Research. 1995;3 Suppl 2:107s-15s.

44. Kimani-Murage EW, Kahn K, Pettifor JM, Tollman SM, Dunger DB, GómezOlivé XF, et al. The prevalence of stunting, overweight and obesity, and metabolic disease risk in rural south African children. BMC Public Health. 2010;10:158.

45. Ohsuka K, Chino N, Nakagaki H, Kataoka I, Oshida Y, Ohsawa I, et al. Analysis of risk factors for dental caries in infants: a comparison between urban and rural areas. Environ Health Prev Med. 2009;14(2):103-10.

46. Popkin B. The dynamics of the dietary transition in the developing world. In: Caballero B, Popkin B, editors. The nutrition transition: diet and disease in the developing world. London: Academic Press; 2002. p. 111-28.

47. Poskitt EM. Countries in transition: underweight to obesity non-stop? Ann Trop Paediatr. 2009;29(1):1-11.

48. Kumar S, Tadakamadla J, Zimmer-Gembeck MJ, Kroon J, Lalloo R, Johnson NW. Parenting practices and children's dental caries experience: a structural 
equation modelling approach. Community Dent Oral Epidemiol. 2017;45(6): 552-8.

49. Chen W, Chen P, Chen SC, Shih WT, Hu HC. Lack of association between obesity and dental caries in three-year-old children. Zhonghua Min Guo Xiao Er Ke Yi Xue Hui Za Zhi. 1998;39(2):109-11.

50. Dye BA, Shenkin JD, Ogden CL, Marshall TA, Levy SM, Kanellis MJ. The relationship between healthful eating practices and dental caries in children aged 2-5 years in the United States, 1988-1994. J Am Dent Assoc. 2004; 135(1):55-66.

51. Hong L, Ahmed A, McCunniff M, Overman P, Mathew M. Obesity and dental caries in children aged 2-6 years in the United States: National Health and nutrition examination survey 1999-2002. J Public Health Dent. 2008;68(4): 227-33.

52. Macek MD, Mitola DJ. Exploring the association between overweight and dental caries among US children. Pediatr Dent. 2006;28(4):375-80.

53. Saunders C, Abel G. Ecological studies: use with caution. Br J Gen Pract. 2014;64(619):65-6. https://doi.org/10.3399/bjgp14X676979.

54. Oliveira MA, Osorio MM. Cow's milk consumption and iron deficiency anemia in children. J Pediatr. 2005;81(5):361-7.

55. Parkin PC, DeGroot J, Maguire JL, Birken CS, Zlotkin S. Severe iron-deficiency anaemia and feeding practices in young children. Public Health Nutr. 2016; 19(4):716-22.

56. Wong C. Iron deficiency anaemia. Paediatr Child Health. 2017;27(11):527-9.

57. Müller O, Krawinkel M. Malnutrition and health in developing countries. Can Med Assoc J. 2005;173(3):279-86.

58. Lagerweij MD, van Loveren C. Declining caries trends: are we satisfied? Curr Oral Health Rep. 2015;2(4):212-7.

59. Duggal P, Petri WA Jr. Does malnutrition have a genetic component? Annu Rev Genomics Hum Genet. 2018;19:247-62.

60. Rutstein SO. Effects of preceding birth intervals on neonatal, infant and under-five years mortality and nutritional status in developing countries: evidence from the demographic and health surveys. Int I Gynaecol Obstetrics. 2005;89(Suppl 1):S7-24.

61. Desai S, Alva S. Maternal education and child health: is there a strong causal relationship? Demography. 1998;35(1):71-81

62. Munthali T, Jacobs C, Sitali L, Dambe R, Michelo C. Mortality and morbidity patterns in under-five children with severe acute malnutrition (SAM) in Zambia: a five-year retrospective review of hospital-based records (2009-2013). Arch Public Health. 2015;73(1):23.

63. UNICEF. Gender Influences on Child Survival, Health and Nutrition: A Narrative Review. 2011. Available at: https://www.unicef.org/Gender_ Influences_on_Child_Survival_a_Narrative_review.pdf. Accessed 15 November, 2019

64. World Health Organisation. Oral health surveys: basic methods. Geneva: World Health Organisation; 1997.

\section{Publisher's Note}

Springer Nature remains neutral with regard to jurisdictional claims in published maps and institutional affiliations.

Ready to submit your research? Choose BMC and benefit from:

- fast, convenient online submission

- thorough peer review by experienced researchers in your field

- rapid publication on acceptance

- support for research data, including large and complex data types

- gold Open Access which fosters wider collaboration and increased citations

- maximum visibility for your research: over $100 \mathrm{M}$ website views per year

At $\mathrm{BMC}$, research is always in progress.

Learn more biomedcentral.com/submissions 